\title{
The method of constant market shares analysis reconsidered
}

\author{
Jan Fagerberg and Gunnar Sollie
}

\begin{abstract}
Constant market shares (CMS) analyses are frequently used in applied studies of export development. This paper reviews the development of the method and argues that it can be considerably improved. A new version of the method is developed which, in addition to the familiar CMS effects, also allows for the calculation of effects reflecting the ability of each country to adapt its export structure to the changes in the commodity and country composition of world imports. The method is applied to a sample of 20 OECD countries for the period 1961-83.
\end{abstract}

This is an Author's Accepted Manuscript of an article published in Applied Economics, Volume 19, Issue 12, 1987 [copyright Taylor \& Francis], available online at: http://www.tandfonline.com/ [DOI:10.1080/00036848700000084]. 


\section{INTRODUCTION}

In the 1950s several studies appeared focusing on structural changes in world trade and production and the consequences of these changes for the export performance and growth of individual countries. One of the earliest contributors, Tyszynski (1951), gave the following outline of the perspective underlying much of this work:

Over the last hundred years, or so, the gradual industrialization of different areas of the world has led to significant changes in the nature of the demand for exports of manufactured commodities. It is a well established proposition that industrial equipment and modern means of transport considerably gained in relative importance at the expense of a number of consumer goods, notably textiles. It is also well known that, in the course of time, the old manufacturing nations exhibited greatly varying degrees of adaptability to this process. It was the purpose of this investigation to give a clearer picture of these changes in world demand for exports and in the competitive position of the leading manufacturing nations of the world.

To find out to what degree the changes in the market shares of different countries on the world market could be explained by the initial commodity composition of each country's exports, he calculated what the aggregate market share of a country on the world market would have been if its market shares in individual commodity groups had remained constant. He referred to the difference between this hypothetical market share and the initial share as change in the market share caused by structural changes in world trade. The residual - the difference between the final and the hypothetical market share - was referred to as change caused by changes in competitiveness. This method is what later became known as 'constant market shares analysis'.

Calculations of the type carried out by Tyszynski soon became popular in applied international economics ${ }^{1}$. A detailed discussion of the method and its possible applications was given by Leamer and Stern (1970) in their influential book on quantitative international economics. They also proposed a new version of the method which has been used in a number of studies ${ }^{2}$. Even if at first glance it does not appear to be the case ${ }^{3}$, they in fact followed Tyszynski to a considerable extent by calculating Tyszynski's 'structural' effect, which they labelled commodity composition effect, and a competitiveness effect which they, as Tyszynski, calculated as a residual. They did, however, add one 'intermediate' effect, the effect of the market distribution of a country's exports. The idea behind this

\footnotetext{
${ }^{1}$ The second to apply the method was Svennilson (1954). Among the early contributors to the development of the method and its application were Baldwin (1958) and Spiegelglas (1959).

${ }^{2}$ Bowen and Pelzman (1984), Ferreira and Rayment (1984), Horwitz (1984) and Utne (1984) just to mention a few, relatively recent examples.

${ }^{3}$ The reason why it does not appear to be the case is that Leamer and Stern calculated effects influencing the growth of exports, not the growth of the market share, as Tyszynski did. This difference, however, is not essential, and the method proposed by Leamer and Stern may easily be converted into a 'market share' version. (A note showing this is available on request from the authors.) The only difference between an 'export growth' and a 'market share' version of the Leamer and Stern method is that the effect of the general rise in world demand disappears when changes in exports are normalized to changes in market shares.
} 
was that since the imports of different countries grow at different rates, the geographical distribution of a country's exports may also affect the export growth of the country.

While it was found to be a useful tool by Leamer and Stern, a much more critical evaluation of the method was given by Richardson (1971). He pointed out that Leamer and Stern's commodity composition and market distribution effects are interdependent, i.e. that the order in which they are calculated matters ${ }^{4}$, and that the values and signs of the various effects may change if the final, instead of the initial, year of the period under consideration is used as base year. However, this criticism (which is assumed basically correct, though not exhaustive) does not seem to have reduced the popularity of the method in empirical studies of export performance.

The purpose of this paper is to develop a new version of the method which avoids the problems and weaknesses outlined above. The main arguments are that the CMS method can be considerably improved in theoretical consistency as well as in empirical applicability if initial years' weights (Laspeyres indices) are used throughout the calculations, and the economic interpretation of the residual terms is made explicit (instead of including them in an arbitrary way in some of the other effects). As a consequence, five effects instead of Leamer and Stern's three are obtained, where the two additional effects reflect a country's ability to adapt its export structure to the changes in the commodity and market composition of world imports, respectively. These additional effects may in some cases be quite important, as shown in the fourth section where the method developed in this paper is applied to a sample of 20 OECD countries for the period 1961-83.

\section{THE 'SEVERAL COMMODITIES / ONE MARKET’ CASE}

The main purpose of this section is to show that Tyszynski's residual effect, which he referred to as caused by changes in competitiveness, can be split into two separate effects, both with a clear cut economic interpretation.

The following symbols will be used:

$n=$ number of commodities;

$0, t=$ subscripts which refer to the initial year and to the final year of the comparison, respectively;

$X_{i}^{k l}=$ country $k$ 's exports of commodity $i$ to country $l$;

$B_{l}^{\prime}=$ country $l$ 's imports of commodity $i$;

$M^{k l}=$ market share of country $k$ (macro share of country $k$ ) in country l's imports; $M^{k l}=\sum_{i} X_{i}^{k l} / \sum_{i} B_{i}^{l}$

$\mathbf{a}^{k l}=$ market shares, by commodity, of country $k$ (micro shares of country $k$ ) in country l's imports; row vector of dimension $n ; \mathbf{a}^{k l}=\left(a_{1}^{k l}, \ldots, a_{n}^{k l}\right)$, where $a_{i}^{k l}=X_{i}^{k l} / B_{l}^{l}$,

$\mathbf{b}^{l}=$ commodity shares of country $l$ 's imports; column vector of dimension $n$; $\mathbf{b}^{l}=\left(b_{1}^{l}, \ldots, b_{n}^{l}\right)^{\prime}$, where $b_{t}^{l}=B_{i}^{l} / \sum_{i} B_{i}^{l}$ and 'denotes transposition.

\footnotetext{
${ }^{4}$ This was mentioned already, in fact, by Leamer and Stern themselves.
} 
The macro share of country $k\left(\mathrm{M}^{\mathrm{k} 1}\right)$ may be written as the inner product of the vector of its micro shares $\left(\mathbf{a}^{\mathrm{kl}}\right)$ and the vector of commodity shares of country l's imports $\left(\mathbf{b}^{1}\right)$ :

$$
M^{k l}=\mathbf{a}^{k l} \mathbf{b}^{l}
$$

The change in $\mathrm{M}^{\mathrm{kl}}$ between time 0 and time $t$ is:

$$
\Delta M^{k l}=M_{t}^{k l}-M_{0}^{k l}
$$

Tyszynski calculated the effect of changes in the commodity shares of the market $\left(\boldsymbol{b}_{t}^{\boldsymbol{l}}-\boldsymbol{b}_{0}^{\boldsymbol{l}}\right)$ using the micro shares of the initial year $\boldsymbol{a}_{0}^{k l}$ as weights, and a competitiveness residual. Regarding the last term, he explicitly assumed that it represented a measure of changes in the micro shares. However, as pointed out by Baldwin (1958) and Spiegelglas (1959), this is the case only as long as some kind of mix of initial and final year weights (Laspeyres and Paasche indices) are used in the calculations. In other words, if the first effect is calculated by using initial-year weights, then the second effect must necessarily be calculated by using final-year weights, if the sum of the two effects is going to be equal to the change in the macro share. If either Laspeyres or Paasche indices are used throughout the calculations, a third (residual) term necessarily appears ${ }^{5}$, as shown below (Laspeyres indices or initial year weights are used):

$$
\Delta M^{k l}=\Delta M_{\mathrm{a}}^{k l}+\Delta M_{\mathrm{b}}^{k l}+\Delta M_{\mathrm{ab}}^{k l}
$$

The first of these terms $\left(\Delta M_{\boldsymbol{a}}^{k l}\right)$ is the effect of changes in the micro shares (market share effect), while the second $\left(\Delta M_{\boldsymbol{b}}^{k l}\right)$ is the familiar commodity composition effect calculated by Tyszynski.

The third (residual) term $\left(\Delta m_{\boldsymbol{a b}}^{k l}\right)$ is the inner product of a vector of changes in micro shares and a vector of changes in commodity shares.

$$
\begin{aligned}
& \Delta M_{a}^{k l}=\left(\mathbf{a}_{t}^{k l}-\mathbf{a}_{0}^{k l}\right) \mathbf{b}_{0}^{l} \\
& \Delta M_{\mathrm{b}}^{k l}=\mathbf{a}_{0}^{k l}\left(\mathbf{b}_{t}^{l}-\mathbf{b}_{0}^{l}\right) \\
& \Delta M_{\mathrm{ab}}^{k l}=\left(\mathbf{a}_{t}^{k l}-\mathbf{a}_{0}^{k l}\right)\left(\mathbf{b}_{t}^{l}-\mathbf{b}_{0}^{l}\right)
\end{aligned}
$$

Does this residual have any economic meaning ${ }^{6}$ ? In the opinion of the present authors it does, because its sign and value depends on the correlation between the changes in the micro shares of the country and the changes in the commodity composition of the market. A formal proof of this statement is

\footnotetext{
${ }^{5}$ That is, neither the Laspeyres nor the Paasche index passes the 'factor reversal test'; cf. Allen (1975) or any standard textbook on index theory.

${ }^{6}$ Both Baldwin (1958) and Spiegelglas (1959) mention that a third 'interaction' effect exists, but they do not discuss its interpretation.
} 
given below. For the sake of simplicity, the superscripts are omitted in the proof:

$$
\Delta M_{\mathrm{ab}}=\left(\mathrm{a}_{\mathrm{t}}-\mathrm{a}_{0}\right)\left(\mathrm{b}_{\mathrm{t}}-\mathrm{b}_{0}\right)
$$

The correlation coefficient between the changes in micro shares and the changes in commodity shares, $r_{\boldsymbol{a b}}$, is defined by

$$
r_{\mathbf{a b}}=\frac{\left(\mathbf{a}_{t}-\mathbf{a}_{0}-\overline{\mathbf{a}}_{t}+\overline{\mathbf{a}}_{0}\right)\left(\mathbf{b}_{t}-\mathbf{b}_{0}-\bar{b}_{t}+\bar{b}_{0}\right)}{\left\|\mathbf{a}_{t}-\mathbf{a}_{0}-\overline{\mathbf{a}}_{t}+\overline{\mathbf{a}}_{0}\right\|\left\|\mathbf{b}_{t}-\mathbf{b}_{0}-\overline{\mathbf{b}}_{t}+\overline{\mathbf{b}}_{0}\right\|}
$$

the symbol || || denotes vector norm, while $\overline{\boldsymbol{a}}_{t}, \overline{\boldsymbol{a}}_{0}, \overline{\boldsymbol{b}}_{t}$ and $\overline{\boldsymbol{b}}_{0}$ are vectors of means, defined by

$$
\begin{aligned}
& \overline{\mathbf{a}}_{t}=(1 / n) \mathrm{a}_{t} \mathrm{ee}^{\prime} \\
& \overline{\mathbf{a}}_{0}=(1 / n) \mathbf{a}_{0} \mathrm{ee}^{\prime} \\
& \overline{\mathrm{b}}_{\mathrm{t}}=(1 / n) \mathrm{e} \\
& \bar{b}_{0}=(1 / n) \mathrm{e}
\end{aligned}
$$

where $\mathbf{e}$ is a column vector of ones and ' denotes transposition. It follows from Equations 8-12 that

$$
\left\|\mathbf{a}_{t}-\mathbf{a}_{0}-\overline{\mathbf{a}}_{t}+\overline{\mathbf{a}}_{0}\right\|\left\|\mathbf{b}_{t}-\mathbf{b}_{0}\right\| r_{\mathrm{ab}}=\left(\mathbf{a}_{t}-\mathbf{a}_{0}-(1 / n) \mathbf{a}_{t} \mathbf{e e}^{\prime}+(1 / n) \mathbf{a}_{0} \mathbf{e e}^{\prime}\right)\left(\mathbf{b}_{t}-\mathbf{b}_{0}\right)
$$

By rearranging:

$$
\left\|a_{t}-\bar{a}_{0}-\bar{a}_{t}+a_{0}\right\|\left\|b_{t}-b_{0}\right\| r_{a b}=\left(a_{t}-a_{0}\right)\left(b_{t}-b_{0}\right)-(1 / n)\left(a_{t}-a_{0}\right) e e^{\prime}\left(b_{t}-b_{0}\right)
$$

Since the sum of the commodity shares is always equal to one, it follows that

$$
\mathbf{e}^{\prime}\left(\mathbf{b}_{\mathbf{t}}-\mathbf{b}_{0}\right)=0
$$

Substituting Equation 15 into Equation 14 gives

$$
\left\|a_{t}-a_{0}-\bar{a}_{t}+\overline{\mathbf{a}}_{0}\right\|\left\|\mathbf{b}_{\mathbf{t}}-\mathbf{b}_{0}\right\| r_{\mathbf{a b}}=\left(\mathbf{a}_{t}-\mathbf{a}_{0}\right)\left(\mathbf{b}_{\mathbf{t}}-\mathbf{b}_{0}\right)
$$

By substituting Equation 16 into Equation 7, the residual can be expressed as the product of the correlation coefficient between the changes in micro shares and the changes in commodity shares, and two terms which are necessarily non-negative. The first of these terms is a measure of the spread of the changes in micro shares, while the second is a measure of the changes in commodity shares (superscripts are reintroduced):

$$
\Delta M_{\mathbf{a b}}^{k l}=\left\|\mathbf{a}_{t}^{k l}-\mathbf{a}_{0}^{k l}-\overline{\mathbf{a}}_{t}^{k l}+\overline{\mathbf{a}}_{0}^{k l}\right\|\left\|\mathbf{b}_{t}^{l}-\mathbf{b}_{0}^{l}\right\| r_{\mathbf{a b}}^{k l}
$$


Thus, this third effect indicates to what degree a country has succeeded in adapting the commodity composition of its exports to the changes in the commodity composition of the market ${ }^{7}$. It was therefore decided to label it the commodity adaptation effect. However, a zero commodity adaptation effect does not indicate that no adaptation takes place, but that the country transforms - or adapts - its export structure at exactly the same rate as the average of all countries exporting to the market in question. Thus, a more correct name would be 'relative adaptation effect', but for convenience the term 'relative' is dropped.

\section{THE 'SEVERAL COMMODITIES/SEVERAL MARKETS' CASE}

The interpretation of the third (residual) term in the 'several commodities/one market' case is quite simple and may to some extent be understood intuitively. In this section the analysis is extended to the more complicated 'several commodities/several markets' case. As in the previous case Laspeyres indices are used throughout the calculations.

The following symbols will be used:

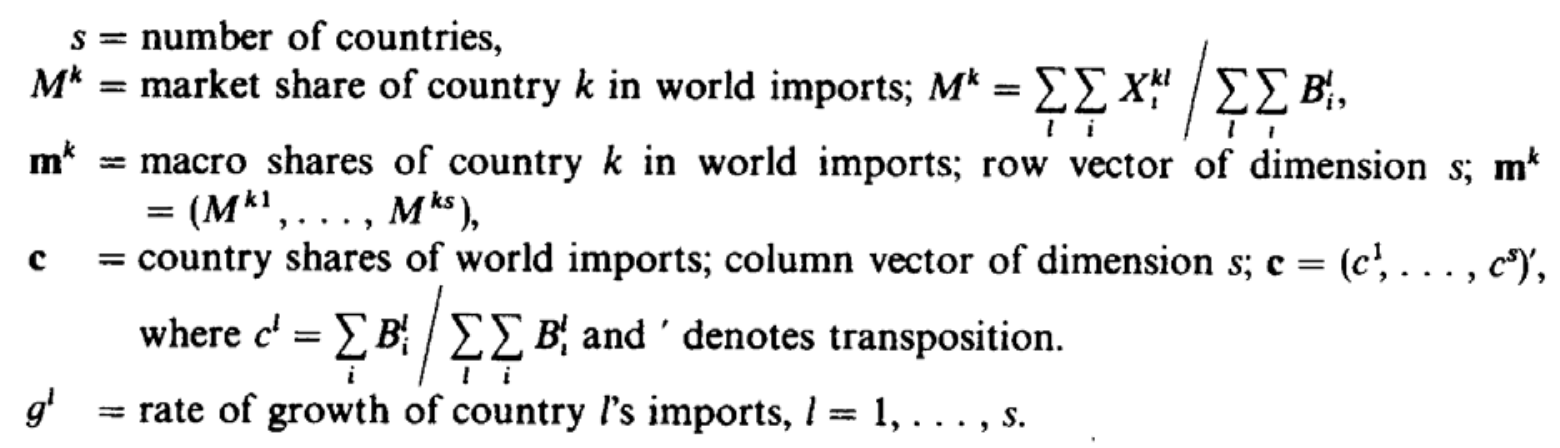

The market share of country $k$ in world imports $\left(M^{k}\right)$ may be written as the inner product of the vector of its macro shares $\left(\mathbf{m}^{k}\right)$ and the vector of country shares of world imports (c):

$$
M^{k}=\mathbf{m}^{k} \mathbf{c}
$$

The change in $\mathrm{M}^{\mathrm{k}}$ between time 0 and time $t$ is

$$
\Delta M^{k}=M_{t}^{k}-M_{0}^{k}
$$

The change in market share $\left(\Delta M^{k}\right)$ may be split into three effects

$$
\Delta M^{k}=\Delta M_{\mathrm{m}}^{k}+\Delta M_{\mathrm{c}}^{k}+\Delta M_{\mathrm{mc}}^{k}
$$

where

\footnotetext{
${ }^{7}$ Another measure of this is of course the correlation coefficient $r_{\boldsymbol{a} \boldsymbol{b}}^{k l}$ itself. However, this coefficient may be quite high, even in cases where the changes in micro shares are quite uniform and the commodity composition of the market does not change much, i.e. when adaptation is of minor economic importance. The commodity adaptation effect, on the other hand, which is the product of the correlation coefficient, the spread in the changes in micro shares, and the degree of change in the commodity composition of the market, would in such cases be quite low. Thus, the commodity adaptation effect is an economically more meaningful measure than the pure correlation coefficient.
} 


$$
\begin{aligned}
& \Delta M_{\mathrm{m}}^{k}=\left(\mathrm{m}_{t}^{k}-\mathrm{m}_{0}^{k}\right) \mathbf{c}_{0} \\
& \Delta M_{\mathrm{c}}^{k}=\mathrm{m}_{0}^{k}\left(\mathrm{c}_{t}-\mathrm{c}_{0}\right) \\
& \Delta M_{\mathrm{mc}}^{k}=\left(\mathrm{m}_{t}^{k}-\mathrm{m}_{0}^{k}\right)\left(\mathrm{c}_{\mathrm{t}}-\mathrm{c}_{0}\right)
\end{aligned}
$$

The first effect is the changes in the macro shares weighted by initial year country shares, while the second effect is the changes in the country shares weighted by initial year macro shares. Thus, the second effect measures the effect on the market share of a country in the world market of changes in the composition of the market. It was therefore decided to label it the market composition effect. The third effect can be interpreted as the degree of success of the country in adapting the market composition of its exports to the changes in the country composition of world imports. Therefore, following the argument of the previous section, it was decided to label it market adaptation effect. Since the proof is analogous to the previous section, the result of the proof is simply stated here. Let $r_{m c}^{k}$ be the correlation coefficient between the changes in macro shares and the changes in country shares, and let $\overline{\boldsymbol{m}}_{0}^{k}$ and $\overline{\boldsymbol{m}}_{t}^{k}$ be vectors of means, then

$$
\Delta M_{\mathbf{m c}}^{k}=\left\|\mathbf{m}_{t}^{k}-\mathbf{m}_{0}^{k}-\overline{\mathbf{m}}_{t}^{k}+\overline{\mathbf{m}}_{0}^{k}\right\|\left\|\mathbf{c}_{t}-\mathbf{c}_{0}\right\| r_{\mathbf{m c}}^{k}
$$

By taking into account Equations 2-6 and the definition of $\mathbf{m}^{k}, \Delta M_{\boldsymbol{m}}^{k}$ may be written as the sum of three effects:

$$
\begin{aligned}
& \Delta M_{\mathrm{m}}^{k}=\Delta M_{\mathrm{a}}^{k}+\Delta M_{\mathrm{b}}^{k}+\Delta M_{\mathrm{ab}}^{k} \\
& \Delta M_{\mathrm{a}}^{k}=\sum_{l}\left(\mathbf{a}_{t}^{k l}-\mathbf{a}_{0}^{k l}\right) \mathbf{b}_{0}^{l} \mathbf{c}_{0}^{l} \\
& \Delta M_{\mathrm{b}}^{k}=\sum_{l} \mathbf{a}_{0}^{k l}\left(\mathbf{b}_{t}^{l}-\mathbf{b}_{0}^{l}\right) \mathbf{c}_{0}^{l} \\
& \Delta M_{\mathbf{a b}}^{k}=\sum_{l}\left(\mathbf{a}_{t}^{k l}-\mathbf{a}_{0}^{k l}\right)\left(\mathbf{b}_{t}^{l}-\mathbf{b}_{0}^{l}\right) \mathbf{c}_{0}^{l}
\end{aligned}
$$

The first effect $\left(\Delta M_{\boldsymbol{a}}^{k}\right)$ is the effect of changes in the micro shares of country $k$ in each market weighted by the commodity composition of each market and the country composition of world imports in the initial year. Following the argument of the previous section, this is labelled the market share effect. By the same token, the second effect $\left(\Delta M_{\boldsymbol{b}}^{k}\right)$ may be labelled the commodity composition effect and the third $\left(\Delta M_{\boldsymbol{a} \boldsymbol{b}}^{k}\right)$ the commodity adaptation effect. Since the proof and interpretation in the latter case is quite analogous to the previous cases, the result of the proof is simply stated here:

$$
\Delta M_{\mathrm{ab}}^{k}=\sum_{l}\left\|\mathbf{a}_{t}^{k l}-\mathbf{a}_{0}^{k l}-\overline{\mathbf{a}}_{t}^{k l}+\overline{\mathbf{a}}_{0}^{k l}\right\|\left\|\mathbf{b}_{t}^{l}-\mathbf{b}_{0}^{l}\right\| r_{\mathrm{ab}}^{k l} \mathbf{c}_{0}^{l}
$$


To sum up, the change in a country's market share in world imports may be split into five effects:

$\Delta M_{\boldsymbol{a}}^{k}=$ the market share effect;

$\Delta M_{\boldsymbol{b}}^{k}=$ the commodity composition effect;

$\Delta M_{c}^{k}=$ the market composition effect;

$\Delta M_{\boldsymbol{a b}}^{k}=$ the commodity adaption effect;

$\Delta M_{\boldsymbol{m} \boldsymbol{c}}^{k}=$ the market adaption effect;

so that

$$
\Delta M^{k}=\Delta M_{\mathrm{a}}^{k}+\Delta M_{\mathrm{b}}^{k}+\Delta M_{\mathrm{c}}^{k}+\Delta M_{\mathrm{ab}}^{k}+\Delta M_{\mathrm{mc}}^{k}
$$

There are two main differences between this and most previous works on the subject. First, Laspeyres indices were used throughout the calculations ${ }^{8}$. Lack of comparability due to differences in weighting procedures is thus avoided. As a consequence, in the general 'several commodities/several markets case' studied by Leamer and Stern, five effects instead of Leamer and Stern's three are obtained ${ }^{9}$. Second, formal proofs have been given of the economic interpretation of the two residual effects.

The interpretation of the residuals has some affinity to a point discussed by Richardson (1971). He pointed out that effects calculated with Laspeyres indices in general differ from effects calculated with Paasche indices, and since he held the choice of index to be relatively arbitrary, he proposed to test the sensitivity of the results by doing both. Richardson focused especially on the difference between Leamer and Stern's market share effects calculated with Laspeyres and Paasche indices, respectively, which in the present notation may be written as follows:

$$
\mathrm{SMC}=\sum_{l}\left[\left(\mathbf{a}_{t}^{k l}-\mathbf{a}_{0}^{k l}\right)\left(\mathbf{b}_{l}^{l}\left(1+\mathbf{g}^{l}\right)-\mathbf{b}_{0}^{l}\right) \sum_{i} B_{i 0}^{l}\right]
$$

Without giving any formal proof of its interpretation, he labelled this difference 'a second measure of competitiveness' (SMC), and claimed that it would be positive if the country increased its market shares in rapidly growing commodities and markets (p. 236), otherwise not. Comparing Equation 31

\footnotetext{
${ }^{8}$ Reymert and Schulz (1985) also use (chained) Laspeyres indices, but contrary to this paper they hold that the residuals thus obtained have no interesting economic interpretation (p. 9).

${ }^{9}$ Brakman et al. (1982) also use a CMS method which in addition to the familiar CMS effects contains two different 'interaction' effects. The first is Richardson's 'second measure of competitiveness', discussed below. Unfortunately, the paper does not discuss the economic interpretation of the various effects, and the references for further information are to two working papers in Dutch. It is not possible, therefore, to discuss their method in detail here. Suffice it to say that their method is rather different from the one developed in this paper, and that there is no exact correspondence between the effects of the two methods.
} 
with Equation 28 reveals that the signs of Richardson's 'second measure of competitiveness' and this paper's commodity adaptation effect are equal in all cases if, and only if $g^{l} \equiv 0$, i.e. if there is no growth in imports. But normally the growth rates of imports will be positive, especially when value data are used. This implies that the sign of Equation 31 for practical purposes depends on the growth of market shares, not on whether these market shares grow especially fast in products or markets that grow faster than average. Richardson should be credited for his attempt to discuss the implications of using different indices in the calculations, but unfortunately his reasoning was not entirely correct ${ }^{10}$.

\section{EMPIRICAL RESULTS}

To test the empirical relevance of the method, it was used to analyse the export performance of 20 OECD countries on the OECD market (defined as the total imports (value) of the 20 OECD countries) in the periods 1961-73 and 1973-83. For each country, the change in market share (macro share) on the OECD market was decomposed into the five effects discussed in the previous section, using Laspeyres indices or 'initial year weights' (1961 for 1961-73 and 1973 for 1973-83). Great care was taken in order to ensure that commodities characterized by high growth in production and trade were specified as separate commodities, since the results also depend on the commodity breakdown used in the calculations ${ }^{11}$. Furthermore, it was decided to exclude oil and gas from the calculations, because if included, the calculations for the post-1973 period would have been totally dominated by the growth in the relative price of oil and gas. The data ${ }^{12}$ were taken from OECD Trade Series C, with the exception of Japan and Finland for 1961, where it was necessary to supplement the OECD data with data from national sources.

The results are given in Tables 1 and 2. The column to the right gives the total percentage change in the market share on the OECD market in the period under consideration. The other five columns add up to this total change. Changes in the structure of OECD trade turned out to be of great importance for the export performance of most OECD countries, especially prior to 1973. During this period (Table 1), the commodity composition effect was strongly positive for a group of relatively advanced industrial countries: Germany, Switzerland, Italy, the UK and the Netherlands, and strongly negative for the least developed countries of the sample: Ireland, Turkey, Greece, Finland, Spain and Portugal. The commodity composition effect contributed negatively to the export performance of Canada, Norway and Denmark during this period, all relatively developed countries with an export structure

\footnotetext{
${ }^{10} \mathrm{He}$ also wrongly states that his 'second measure of competitiveness' is the same as the Baldwin-Spiegelglas 'interaction effect'.

${ }^{11}$ The commodity classification used is given in the Appendix.

${ }^{12}$ As is well known, data on exports and imports are not directly comparable. For instance, the value of total intra-OECD trade is not the same according to exports and imports statistics. To assure consistency, only import data were used in the calculations. This implies that the export from country $k$ to country $I$ of commodity $i$ is defined as the import of country $I$ from country $k$ of commodity $i$, or:

$$
X_{i}^{k l}=B_{i}^{l k}
$$
}


dominated by raw materials and semi-finished products. The results for the post-1973 period (Table 2) resemble the results from the preceding period, but the effects were in general smaller.

The market composition effect was generally less important than the commodity composition effect, especially prior to 1973. It turned out to be strongly negative for Ireland, and to a lesser degree also for the Nordic countries. After 1973 the market composition effect was of special importance (strongly positive) for Canada, Ireland and Japan.

Even if commodity and market composition effects were important, and in some cases decisive, for most countries the development of market shares within individual commodity groups was the most important single factor. The general picture both before and after 1973 was that some of the least developed countries of the sample won market shares at the expense of some of the more developed ones. Prior to 1973, the five most important gainers were Portugal, Japan, Greece, France and Spain; after 1973 Japan, Ireland, Spain, Greece and Italy. Moving to the important losers, prior to 1973, there were only four: the UK, the USA, Turkey and Switzerland. After 1973, the five most important losers were Denmark, Sweden, Norway, the UK and Canada.

The calculations show that the adaptation effects in some cases were quite important, the single most important example being Japan before 1973, where approximately $40 \%$ of the increase in market shares was due to the commodity adaptation effect. During this period, commodity adaptation also contributed positively to the export performance of Canada, Turkey, Greece and Finland, and negatively for Switzerland, Germany, the UK, the Netherlands and Italy. Thus, there seems to be a tendency that countries with a positive commodity composition effect adapt less well than countries with a negative commodity composition effect, and vice versa. After 1973 the differences were smaller; Ireland and Japan may be mentioned on the positive side, Greece and Switzerland on the negative side. Market adaptation effects were in general less important, with Japan (on the positive side) and Finland and Portugal (on the negative side) as possible exceptions. 
Table I. Export performance of 20 OECD countries on the OECD market, 1961-73

\begin{tabular}{lcccccc}
\hline & $\begin{array}{c}\text { Commodity } \\
\text { compostion }\end{array}$ & $\begin{array}{c}\text { Market } \\
\text { composition }\end{array}$ & $\begin{array}{c}\text { Market } \\
\text { share }\end{array}$ & $\begin{array}{c}\text { Commodity } \\
\text { adaption }\end{array}$ & $\begin{array}{c}\text { Market } \\
\text { adaption }\end{array}$ & Total \\
\hline Canada & -28.51 & 1.17 & -1.57 & 15.05 & 2.86 & -11.00 \\
\hline USA & -0.44 & 0.81 & -21.32 & 2.14 & -2.03 & -20.84 \\
\hline Japan & -5.69 & 3.61 & 58.12 & 40.69 & 1.58 & 98.31 \\
\hline Austria & -1.35 & 1.03 & 4.18 & -1.07 & -6.38 & -3.60 \\
Belgium & -7.74 & 3.14 & 12.26 & 6.71 & 4.07 & 18.44 \\
\hline Denmark & -11.10 & -9.68 & 0.18 & -0.32 & -0.55 & -21.48 \\
Finland & -23.07 & -6.16 & 3.21 & 7.25 & -5.58 & -24.34 \\
\hline France & 1.38 & 4.31 & 24.51 & -0.70 & 0.14 & 29.64 \\
\hline Germany & 17.14 & 1.74 & 1.79 & -9.11 & 0.60 & 12.17 \\
\hline Greece & -23.23 & 2.54 & 35.05 & 7.24 & 1.33 & 22.93 \\
\hline Ireland & -27.21 & -19.66 & 20.54 & 2.16 & 5.82 & -18.35 \\
\hline Italy & 12.89 & 2.66 & 12.18 & -6.22 & 4.11 & 25.62 \\
\hline Netherlands & 6.05 & 1.74 & 17.13 & -7.78 & 0.43 & 17.57 \\
\hline Norway & -13.76 & -7.99 & 17.93 & -2.93 & -4.03 & -10.78 \\
\hline Portugal & -21.13 & -0.78 & 64.82 & 3.06 & -11.48 & 34.49 \\
\hline Spain & -22.89 & 0.00 & 23.73 & 3.77 & 3.12 & 7.74 \\
Sweden & -5.35 & -5.96 & 1.99 & -2.82 & -2.67 & -14.80 \\
\hline Switzerland & 15.96 & 3.50 & -8.89 & -10.22 & -3.78 & -3.53 \\
\hline Turkey & -24.62 & 4.63 & -16.15 & 8.16 & -2.66 & -30.63 \\
\hline UK & 7.02 & -4.22 & -25.15 & -8.56 & 1.69 & -29.22 \\
\hline
\end{tabular}

Table 2. Export performance of 20 OECD countries on the OECD market, 1973-83

\begin{tabular}{lcccccc}
\hline & $\begin{array}{c}\text { Commodity } \\
\text { compostion }\end{array}$ & $\begin{array}{c}\text { Market } \\
\text { composition }\end{array}$ & $\begin{array}{c}\text { Market } \\
\text { share }\end{array}$ & $\begin{array}{c}\text { Commodity } \\
\text { adaption }\end{array}$ & $\begin{array}{c}\text { Market } \\
\text { adaption }\end{array}$ & Total \\
\hline Canada & -4.24 & 15.15 & -8.69 & -2.61 & -2.17 & -2.56 \\
\hline USA & 3.63 & 1.35 & -1.53 & 1.28 & -0.15 & 4.59 \\
\hline Japan & 3.77 & 10.32 & 41.01 & 6.18 & 4.87 & 66.14 \\
\hline Austria & -5.56 & -2.40 & 16.80 & 0.78 & -1.27 & 8.34 \\
Belgium & -4.71 & -3.31 & -12.39 & 0.47 & 0.78 & -19.15 \\
\hline Denmark & -9.09 & -0.31 & 7.41 & -2.13 & -2.12 & -6.22 \\
\hline Finland & -10.66 & -2.03 & 9.54 & 1.47 & -3.15 & -4.83 \\
\hline France & -1.10 & -3.63 & -4.33 & 2.79 & 0.63 & -5.65 \\
\hline Germany & 1.24 & -3.66 & -6.78 & 0.07 & 0.52 & -8.61 \\
\hline Greece & -10.41 & -1.51 & 23.01 & -5.41 & -0.61 & 5.07 \\
\hline Ireland & -7.19 & 11.04 & 34.00 & 11.93 & -3.45 & 46.33 \\
\hline Italy & 1.62 & -0.90 & 18.31 & -7.45 & -0.33 & 11.25 \\
\hline Netherlands & -1.99 & -3.12 & -7.38 & 1.45 & 0.31 & -10.71 \\
\hline Norway & -7.77 & -3.17 & -10.44 & 0.26 & -0.94 & -22.05 \\
\hline Portugal & -4.31 & 2.24 & 9.03 & -1.73 & -3.92 & 1.32 \\
\hline Spain & -3.99 & 1.67 & 23.50 & 2.58 & -2.32 & 21.45 \\
\hline Sweden & -5.14 & -3.48 & -11.21 & -2.42 & -0.18 & -22.42 \\
\hline Switzerland & 5.95 & 0.00 & 10.81 & -4.13 & -0.33 & 12.31 \\
\hline Turkey & -14.76 & -1.37 & 13.27 & -3.64 & 0.65 & -5.85 \\
\hline UK & 4.07 & 1.22 & -10.35 & -0.95 & -1.25 & -7.25 \\
\hline
\end{tabular}




\section{CONCLUDING REMARKS}

The method of constant market shares analysis was developed by Tyszynski (1951) and others, and further elaborated by Leamer and Stern (1970), as a tool to study the relation between structural changes in world trade and the export performance of individual countries. However, both Tyszinski's and Leamer and Stern's versions of the method suffer from major weaknesses: An inconsistent use of indices, and an insufficient discussion of how the residuals in the calculations should be interpreted. As a consequence, doubts have been expressed - starting with Richardson (1971) - regarding the interpretation of the various effects and the usefulness of the method in general.

The method developed in this paper differs from most other works on the subject in at least two respects: Laspeyres indices are used consistently throughout the calculations, and proofs are given for the economic interpretation of the residuals. As a consequence, five effects instead of Leamer and Stern's three are obtained. The two additional effects were found to be measures of a country's ability to adapt its export structure to change in the commodity and market composition of world imports, respectively. Thus, the method developed in this paper provides a solution to the problem originally posed but only partly solved by Tyszynski: to develop a method which gives a clear picture of the adaptability of different countries to changes in the patterns of world trade.

When applied to a sample of 20 industrial countries between 1961 and 1983, several interesting results emerged. First, the structural changes in OECD trade turned out to have been quite important for the export performance of most countries during the period under consideration. In general, the structural changes contributed positively to the export performance of the economically most advanced countries of the sample, and negatively to the export performance of the less developed ones. Second, differences in adaptability were in some cases quite important, especially for Japan, but also for a number of other countries. In general, the economically most advanced countries adapted less well than the others. Third, changes in market shares within individual commodity groups and markets turned out to be the single most important factor shaping the export performance of the OECD countries. The general picture was that some of the economically less developed countries of the sample won market shares at the expense of some of the more developed ones. 


\begin{tabular}{|c|c|c|}
\hline Classification of products & SITC Rev. 1 & SITC Rev. 2 \\
\hline \multicolumn{3}{|l|}{$\begin{array}{l}\text { (101) Products based on natural } \\
\text { resources }\end{array}$} \\
\hline $\begin{array}{l}\text { l. Animals, meat, and meat } \\
\text { preparations }\end{array}$ & $00,01,091.3,411.3$ & $00,01,091.3,411.3$ \\
\hline 2. Dairy products and eggs & 02 & 02 \\
\hline 3. Fish and fish preparations & $03,411.1$ & $03,411.1$ \\
\hline 4. Cereals and cereal preparations & 04 & 04 \\
\hline 5. Feeding-stuff for animals & 08 & 08 \\
\hline 6. Skins and leather manufactures & 21,61 & 21,61 \\
\hline 7. Wood and wood manufactures & 24,63 & 24,63 \\
\hline 8. Pulp and paper & 25,64 & 25,64 \\
\hline 9. Textiles & 26,65 & 26,65 \\
\hline 10. Iron ore & 281 & 281 \\
\hline 11. Iron, steel and ferro alloys & 67 & 67 \\
\hline 12. Aluminum & 684 & 684 \\
\hline $\begin{array}{l}\text { 13. Other products based on natural } \\
\text { resources }\end{array}$ & $\begin{array}{l}05,06,07,091.4,099,11, \\
12,22,23,27,282,283, \\
284,285,286,29,32,35, \\
42,43,62,66,681,682, \\
683,685,686,687,688, \\
689\end{array}$ & $\begin{array}{l}05,06,07,091.4,098,11, \\
12,22,23,27,282,286, \\
287(-: 32), 288,289,29,32, \\
35,42,43,62,66,681,682, \\
683,685,686,687,688,689, \\
699.9\end{array}$ \\
\hline \multicolumn{3}{|l|}{ (102) Oil and gas } \\
\hline 14. Oil and gas & 33,34 & 33 (- : 5.2), 34 \\
\hline \multicolumn{3}{|l|}{ (103) Chemicals } \\
\hline 15. Organic chemicals & 512 & 51 \\
\hline 16. Inorganic chemicals & 513,514 & $522,523,287.32$ \\
\hline 17. Dyestuffs, colouring materials & 53 & 53 \\
\hline 18. Pharmaceuticals & 54 & 54 \\
\hline 19. Fertilizers & 56 & 56 \\
\hline 20. Plastic materials & 581.1:2 & 582, 583, 893.91:2 \\
\hline 21. Other chemicals & $\begin{array}{l}\text { 515,52, 55, 57,581.3:9, } \\
59\end{array}$ & $\begin{array}{l}335.2,524,55,57,584,585 \text {, } \\
\text { 59, 894.63, 899.39, } 951.66\end{array}$ \\
\hline \multicolumn{3}{|l|}{$\begin{array}{c}\text { (104) Engineering, electronics and } \\
\text { transport equipment }\end{array}$} \\
\hline 22. Power generating machinery & 711 & 711, 712, 713, 714, 718 \\
\hline $\begin{array}{l}\text { 23. Machinery for special industries or } \\
\text { processes }\end{array}$ & $\begin{array}{l}\text { 712, 715, 717, 718, } \\
\text { 719.3:5:8 }\end{array}$ & 72, 73 (- :7.32) 744, 745.1 \\
\hline 24. Heating and cooling equipment & 719.1 & $741(-: 31)$ \\
\hline 25. Pumps and centrifuges & 719.2 & 742,743 \\
\hline 26. Typewriters and office machines & 714.1:9 & 751.1:81:88, 759.11: 15 \\
\hline 27. Computers and peripherals & $714.2: 3$ & 751.2, 752, 759.9 \\
\hline 28. Semiconductors & 729.3 & 776 \\
\hline 29. Telecommunications & 724.9 & $764(-: 99)$ \\
\hline $\begin{array}{l}\text { 30. Machinery for production and } \\
\text { distribution of electricity }\end{array}$ & 722, 723, 729.9 & $\begin{array}{l}\text { 771, 772, 716, 773, } 778.8(-: \text { 5), } \\
\text { 737.32, 741.31 }\end{array}$ \\
\hline 31. Consumer electronics & $724.1: 2,891.1$ & 761, 762, 763, 764.99 \\
\hline 32. Domestic electrical equipment & 725 & 775 \\
\hline $\begin{array}{l}\text { 33. Scientific instruments photographic } \\
\text { supplies, watches and clocks }\end{array}$ & 726, 729.5: 7, 861, 862, 864 & $\begin{array}{l}\text { 751.82, 759.19, 774, 778.85, } \\
87,88(-: 3)\end{array}$ \\
\hline 34. Road motor vehicles & 732 & $78(-: 5(-: 1: 39))$ \\
\hline
\end{tabular}




\begin{tabular}{|c|c|c|}
\hline 35. Aircraft & 734 & $792(-: 83)$ \\
\hline $\begin{array}{l}\text { 36. Ships and boats } \\
\text { (incl. oil rigs) }\end{array}$ & 735 & 793 \\
\hline 37. Other engineering products & $\begin{array}{l}\text { 719.6:7:9,729.1:2:4:6, } \\
\text { 731, } 733\end{array}$ & $\begin{array}{l}\text { 745.2, 749, } 778 \text { (- :8), } \\
785.2: 31,786,791\end{array}$ \\
\hline \multicolumn{3}{|c|}{ (105) Traditional industrial products } \\
\hline 38. Manufactures of metal & 69,719.4,812.1:3 & 69 (- : 9.9), 812.1 \\
\hline 39. Furniture & 82 & 82 \\
\hline 40. Clothing & 84 & 655.3,658.98,84( - :8.21) \\
\hline 41. Industrial products & $\begin{array}{l}812.2: 4,83,85,863,891, \\
2: 4: 8: 9,892,893,894,895,896 \text {, } \\
897,899,9\end{array}$ & $\begin{array}{l}\text { 792.83, 812.2:4, 83, 848.21, 851, } \\
\text { 883, 892, 893 (- : } 91 \text { : 92), } 894 \text { (- } \\
: 63), 895,896,897,898,899.1: \\
3(-: 9): 4: 6: 7: 8: 9,9\end{array}$ \\
\hline $\begin{array}{l}\text { (106) Sum of all products } \\
\text { 42. Sum off all products }\end{array}$ & & \\
\hline
\end{tabular}

The abbreviations should be read as the following examples show:

891.1:3 should be read as $891.1+891.3$

899.3 (- :9) should be read as $899.3-899.39$

Commodity no. 14 (oil and gas) was not included in the calculations. 


\section{ACKNOWLEDGEMENTS}

The work presented in this paper started while the authors worked together at the Central Bureau of Statistics, Oslo in 1984-5. The empirical calculations were carried out later at the University Center of Aalborg as a part of a project on international competitiveness for which Fagerberg is responsible. Economic support from the Norwegian Research Council for Social Sciences and the Humanities (NAVF) is gratefully acknowledged. We are indebted to Bent Dalum and Leif Seerup, University Center of Aalborg, for assistance in data work and calculations, and to Aadne Cappelen, Petter Frenger, and Anders Rygh Svendsen, all at the Central Bureau of Statistics, for valuable comments and suggestions at different stages of the development of this paper.

\section{REFERENCES}

Allen, R. G. D. (1975), Index Numbers in Theory and Practice, Macmillan, London.

Baldwin, R. E. (1958), The commodity composition of world trade: selected industrial countries 1900-1954, Review of Economics and Statistics, 40, 50-71.

Bowen, H. P. and Pelzman, J. (1984) US export competitiveness: 1962-77, Applied Economics, 16, 461-73.

Brakman, S., Jepma, C. J. and Kuipers, S. K. (1982), The deterioration of the Netherlands' export performance during the late 1970's, De Economist, 3, 360-80.

Feirrara, M.P. and Rayment, P. (1984), Exports of manufactures from South European countries, Journal of World Trade Law, 18, 235-51.

Horwitz, C. (1984), Export performance of the Nordic countries 1965-1982, in Economic Growth in a Nordic Perspective (Ed.) G. Eliasson et al., DOR Sekretariet, Copenhagen/Helsinki/Stockholm/Bergen, 260-84.

Leamer, E. E. and Stern, R. M. (1970), Quantative International Economics, Aldine Publishing Co., Chicago.

Reymert, R. and Schultz, C. E. (1985), Eksport og markedsstruktur, Rapporter 85/5, Central Bureau of Statistics, Oslo. 
Richardson, J. D. (1971) Constant-market-shares analysis of export growth, Journal of International Economics, 1, 227-39.

Spiegelglas, S. (1959) World exports of manufactures, 1956 vs.1937, The Manchester School, 27, 111-39.

Svennilson, I. (1954) Growth and Stagnation in the European Economy, United Nations Economic Commission for Europe, United Nations Publications, Geneva.

Tyszynski, H. (1951) World trade in manufactured commodities, 1899-1950, The Manchester School, 19, 272-304.

Utne, A. (1984) The EFTA countries' export performance for manufactured goods 1970-1982, Occasional Paper no. 7, EFTA, Geneva. 